\title{
The antioxidant activity of steamed ginger and its protective effects on obesity induced by high-fat diet in C57BL/6J mice
}

\author{
Hee-Jeong Kim ${ }^{1 *}$, Bohkyung Kim²*, Eun-Gyung Mun', Soon-Yeon Jeong ${ }^{3}$ and Youn-Soo Cha ${ }^{15}$ \\ ${ }^{1}$ Department of Food Science and Human Nutrition, Chonbuk National University and Obesity Research Center, 567 Baekje-daero, Dukjin-gu, Jeonju, Jeonbuk 54896, Korea \\ ${ }^{2}$ Department of Food Science and Nutrition, Pusan National University, Busan 46241, Korea \\ ${ }^{3}$ Healthy Local Food Branding Agency, Jeonbuk, 55310, Korea
}

BACKGROUND/OBJECTIVES: Ginger, a root vegetable, is known to have antioxidant and antiobesity effects. Preparation, such as by steaming, can affect the chemical composition of prepared root vegetables or herbs and can change their functional activities. In the present study, we investigated the protective effects of steamed ginger against oxidative stress and steatosis in C57BL/6J mice fed a high-fat diet.

MATERIAL/METHODS: The levels of polyphenols and flavonoids in two different extracts of steamed ginger, i.e., water extract (SGW) and ethanolic extract (SGE); as well, their antioxidant activities were examined. Forty male C57BL/6J mice were fed a normal diet (ND, $n=10$ ), high-fat diet (HFD, 60\% fat, w/w, $n=10$ ), HFD supplemented with $200 \mathrm{mg} / \mathrm{kg}$ of SGE or garcinia (GAR) by weight (SGED or GARD, respectively, $n=10$ ) for 12 weeks. Serum chemistry was examined, and the expressions of genes involved in lipid metabolism were determined in the liver. Histological analysis was performed to identify lipid accumulations in epididymal fat pads and liver.

RESULTS: The SGE had higher contents of polyphenols and flavonoids and higher DPPH and ABTS $^{+}$free radical scavenging activities compared to those of SGW. Treatment with SGE or GAR significantly decreased the HFD-induced weight gain. Both SGE and GAR significantly reduced the high serum total cholesterol (TC), triglyceride (TG) and low-density lipoprotein levels induced by HFD. Compared to ND, HFD significantly increased hepatic TC and TG levels. SGE or GAR supplementation significantly decreased the increase of hepatic lipids by HFD. Interestingly, SGE had a more significant effect in reducing hepatic TC and TG levels than GAR. Furthermore, hepatic genes involved in lipogenesis and lipolysis were altered in both the SGED and GARD groups.

CONCLUSIONS: The present study indicates that steamed ginger supplementation can decrease plasma TC and TG and can inhibit liver steatosis by regulating the expressions of hepatic genes.

Nutrition Research and Practice 2018;12(6):503-511; https://doi.org/10.4162/nrp.2018.12.6.503; pISSN 1976-1457 elSSN 2005-6168

Keywords: Steamed ginger extract, antioxidant, diet-induced obesity

\section{INTRODUCTION}

The global prevalence of obesity has markedly increased in the past few decades. The risk of premature death from obesity-associated metabolic diseases such as cardiovascular disease (CVD), nonalcoholic fatty liver disease (NAFLD), type 2 diabetes, osteoarthritis, and some cancers has significantly increased in concert with the rising obesity rates [1]. According to WHO, obesity is defined as a medical condition in which the body has excessive fat accumulation to the extent that it has an adverse effect on health. Recently, obesity has been considered a metabolic disorder that exerts a state of chronic oxidative stress and low-grade inflammation followed by systemic changes in the body [2]. In obesity, oxidative stress is induced by increased productions of local and/or systemic pro-inflammatory adipocytokines or adipokines in adipose tissue [3,4]. Oxidative stress is an imbalance between the systemic production of free radicals and the capacity of the biological antioxidant defense system to counteract or detoxify these radicals. Oxidative stress can cause damage to all components of the cell including proteins, lipids, and DNA, which can contribute to many physiological and pathological conditions [5]. Antioxidants that can attenuate oxidative stress receive research attention as preventative and therapeutic compounds against oxidative stress associated metabolic diseases.

Ginger (Zingiber officinale), a popular spice and vegetable in worldwide, is used as a traditional medicine in China and East Asia countries to treat rheumatism, toothaches, asthma, constipation, and diabetes [6-8]. Many studies on ginger are focused on fresh ginger and their bioactive components. In several

\footnotetext{
${ }^{\S}$ Corresponding Author: Youn-Soo Cha, Tel. 82-63-270-3822, Fax. 82-860-486-3674, Email. cha8@jbnu.ac.kr

Received: April 9, 2018, Revised: April 24, 2018, Accepted: October 24, 2018

* These two authors contributed equally to this study.

This is an Open Access article distributed under the terms of the Creative Commons Attribution Non-Commercial License (http://creativecommons.org/licenses/by-nc/3.0/) which permits unrestricted non-commercial use, distribution, and reproduction in any medium, provided the original work is properly cited.
} 
studies, ginger and its active compounds have been shown to exert strong antioxidant activities in vitro and in vivo [9-11]. Interestingly, the antioxidant potencies of ginger or its active components were different in fresh and dried ginger [12]. Root vegetables such as ginseng, garlic, and ginger may undergo a heating process when being used as a spice, prepared vegetable, or traditional medicine. Heating processes, including steaming, affect the chemical composition of root vegetables or herbs and change their functional activities [13-22]. However, little has been reported about the protective effects of steamed ginger on oxidative stress and diet-induced obesity (DIO). In the present study, we investigated the in vitro radical scavenging activity of steamed ginger and its protective effects $\mathrm{DIO}$ in a mouse model.

\section{MATERIALS AND METHODS}

\section{Steamed ginger extract preparation}

Ginger was steamed and then extracted with either water or ethanol by Healthy Local Food Branding Agency (Wanju, Jeonbuk, South Korea). For standardization of the extracts, the marker compound was set to 6-shogaol, and the samples were analyzed using HPLC at a detection wavelength of $230 \mathrm{~nm}$. The ginger extracts were standardized to the concentration of 6-shogaol.

\section{Total polyphenol and total flavonoid assay}

The total polyphenol contents of the two extracts of steamed ginger were determined by using Folin-Ciocalteu's reagent and the method of Velioglu et al. [23]. In brief, a $100 \mu \mathrm{L}$ of sample was added to $2 \%$ sodium carbonate, followed by addition of $100 \mu \mathrm{L}, 50 \%$ (v/v) Folin-Ciocalteu's reagent. Then, the mixture was incubated for $30 \mathrm{~min}$, and the absorbance was read at 750 $\mathrm{nm}$ by using a UV-visible spectrophotometer (Shimadzu, Kyoto, Japan). The total polyphenol content was expressed as milligrams of gallic acid equivalent per gram of dried sample (mg.GAE/g). The reagents used in the experiments were sodium carbonate, Folin-Ciocalteu's reagent, gallic acid, sodium nitrite (SigmaAldrich, St. Louis, MO, USA) aluminum chloride hexahydrate (Duchefa, Haarlem, Netherlands) and sodium hydroxide (Samchun Chemicals, Phyeontaek, Korea).

Total flavonoid content was measured by applying the method of Jia and Wo with minor modifications [24]. Briefly, $25 \mu \mathrm{L}$ of the extract were mixed with $125 \mu \mathrm{L}$ of distilled water, and $8 \mu \mathrm{L}$ of $5 \%$ sodium nitrite were added. To the mixture, $15 \mu \mathrm{L}$ of $10 \%$ aluminum chloride hexahydrate were added and the mixture incubated for $6 \mathrm{~min}$. Next, $50 \mu \mathrm{L}$ of $1 \mathrm{M}$ sodium hydroxide (Samchun Chemicals, Phyeontaek, Korea) were added and the mixture thoroughly mixed, followed by the addition of $27 \mu \mathrm{L}$ of distilled water. The absorbance was measured at $530 \mathrm{~nm}$ using a microplate reader (MRX II; Dynex Technologies, Chantilly, VA, USA). Quercetin (Sigma-Aldrich, St. Louis, MO, USA) was used as the standard, and the total flavonoid content is expressed as milligrams of quercetin equivalents per gram of dried sample $(\mathrm{mg} \cdot \mathrm{QE} / \mathrm{g})$.

\section{Radical scavenging activity}

The reducing power was determined by using the method of Mau et al. [25]. First, $250 \mu \mathrm{L}$ of $0.2 \mathrm{M}$ sodium phosphate buffer ( $\mathrm{pH}$ 6.6) were added to $250 \mu \mathrm{L}$ of an extract followed by the addition of $250 \mu \mathrm{L}$ of $1 \%(\mathrm{w} / \mathrm{v})$ potassium ferricyanide (Sigma-Aldrich, St. Louis, MO, USA) and incubation of the mixture for $20 \mathrm{~min}$ at $50^{\circ} \mathrm{C}$. Then, the mixture was added to $250 \mu \mathrm{L}$ of $1 \%(\mathrm{w} / \mathrm{v})$ trichloroacetic acid (Sigma-Aldrich, St. Louis, MO, USA) and centrifuged at 10,000 rpm (Micro 17R; Vision Scientific, Seoul, Korea) for $10 \mathrm{~min}$. The supernatant $(500 \mu \mathrm{L})$ was mixed with $500 \mu \mathrm{L}$ of distilled water and $100 \mu \mathrm{L}$ of $0.1 \%$ $(w / v)$ ferric chloride (Sigma-Aldrich, St. Louis, MO, USA). The reducing power of the sample was recorded at an absorbance of $700 \mathrm{~nm}$ by using a spectrophotometer.

The free radical scavenging activity of each extract (concentration: $1 \mathrm{mg} / \mathrm{mL}$ ) was measured colorimetrically with slight modification as described, and the DPPH radical scavenging activity was calculated by using the equation in the Hatano method [26]. DPPH (160 $\mu$; Sigma-Aldrich, St. Louis, MO, USA) was added to $40 \mu \mathrm{L}$ of an extract. The mixture was then incubated at $37^{\circ} \mathrm{C}$ for $30 \mathrm{~min}$ in the dark, and its absorbance was determined. The same concentration of trolox was used as the positive control, and ethanol was used as the negative control. The total antioxidant activity of the different extracts of steamed ginger was determined by determining the 2,2 -azino-bis-(3-ethylbenzothiazoline-6-sulfonic acid) diammonium salt (ABTS) scavenging activity following to the method and equation described by Re [27]. Briefly, $7.4 \mathrm{mM}$ ABTS (SigmaAldrich, St. Louis, MO, USA) was reacted with a $2.6 \mathrm{mM}$ potassium persulfate (Sigma-Aldrich, St. Louis, MO, USA) solution and incubated overnight to generate ABTS radical cations. The $\mathrm{ABTS}^{+}$solution was then diluted in ethanol to absorbance values between 1.2 and 1.5 by using mol absorbance $(\varepsilon=1.6 \times 104$ $\left.\mathrm{M}^{-1} \cdot \mathrm{cm}^{-1}\right)$. Then, $50 \mu \mathrm{L}$ of each extract were added to $950 \mu \mathrm{L}$ of the diluted $\mathrm{ABTS}^{+}$solution, and the change in absorbance was measured after $30 \mathrm{~min}$ at room temperature. The same concentration of trolox (Sigma-Aldrich, St. Louis, MO, USA) was used as the positive control, and ethanol was used as the negative control.

\section{Animal care and diet}

Male 8-week-old C57BL/6J mice were purchased from Charles River Laboratories (Tokyo, Japan) and randomly assigned to a control diet (ND; $10 \%$ fat by weight, $n=10 ; \mathrm{D} 12450 \mathrm{~B}$, Research Diets, New Brunswick, NJ, USA), a high-fat diet (HFD; 60\% fat by weight, $n=10$; D12492, Research Diets, New Brunswick, NJ, USA) or a HFD with the addition of $200 \mathrm{mg} / \mathrm{kg}$ of SGE or garcinia (GAR) by weight (SGED or GARD, respectively, $n=10$ ). The GAR, a plant well-known for its antiobesity effect, was used as a positive control. Mice were fed one of the experimental diets for 12 weeks. The compositions of the experimental diets are shown in Table 1. Mice were housed in polycarbonate cages under $12 \mathrm{~h}$ light/dark cycles. Body weight and food consumption were recorded weekly, and blood samples were collected monthly from the lateral tail vein. Mice were starved for $12 \mathrm{~h}$ and anesthetized by using an ethyl ester. Blood was collected in a tube and centrifuged at $1,000 \times \mathrm{g}$ for $15 \mathrm{~min}$ at $4^{\circ} \mathrm{C}$ for serum collection. Liver and epididymal adipose tissue were harvested, snap frozen in liquid nitrogen or fixed in $10 \%$ formalin and stored at $-80^{\circ} \mathrm{C}$ until use. All animal procedures 
were approved by the Institutional Animal Care and Use Committee at the Chonbuk National University (CBU 2016-101).

Serum chemistry and liver lipid measurements

Liver lipids for analysis were extracted by modified Folch's methods as previously described [28]. Serum and liver triglyceride (TG) and total cholesterol (TC) concentrations were analyzed using a commercial assay kit (Asan Pharmaceutical, Seoul, Korea). Serum concentration of high-density lipoprotein cholesterol (HDL-C) was measured by using a commercial kit (Asan Pharmaceutical, Seoul, Korea). Serum low-density lipoprotein cholesterol (LDL-C) concentration was calculated by applying the Friedewald formula [29]. Concentrations of alanine transaminase (ALT) and aspartate transferase (AST) in serum were determined by using a clinical chemistry analyzer (Fuji Dri-Chem 3500, Fuji Photo Film, Tokyo, Japan). Serum glucose and insulin concentrations were determined by using a glucometer (Accu-check, Roche, Mannheim, Germany) and a mouse ultrasensitive insulin ELISA kit (Alpeo, Sale, MA, USA), respectively. The levels of leptin and adiponectin in serum were measured by using assay kits (R\&D Systems, Minneapolis, MN, USA) according to the manufacturer's protocols.

\section{Quantification of abdominal fat using micro-computed tomography (micro-CT)}

Total body fat content was determined by using by highresolution in vivo micro-CT (Skyscan, Kontich, Belgium). Mice were anesthetized using a mixture of zoletil 50 and rompun (1:1), and micro-CT images of the abdomen were captured at the level of the L1-L5 inter-vertebral disks. The total fat level was analyzed by using Skyscan software version 1.16.4.1 (Skyscan, Kontich, Belgium).

\section{Histology of liver and fat tissue}

Tissue samples were fixed in 10\% formalin and embedded in paraffin. The tissue sample was cut into $5 \mu \mathrm{m}$ thick sections and stained with hematoxylin-eosin (H\&E) stain. Stained areas were viewed by using an Axiophot Zeiss Z1 microscope (Carl Zeiss, Gottingen, Germany) at 3,200 magnification and images were analyzed with SIS 3.2 software (Soft-Imaging System).

Gene expression analysis by quantitative real-time PCR (qRT-PCR)

Total RNA was extracted by using TRIzol reagent (Invitrogen, Grand Island, NY, USA) and qRT-PCR analysis was used to determine gene expression as previously described [30] using the SYBR Green PCR Master Mix (Applied Biosystems, Foster City, CA, USA) and a 7500 real-time PCR system (Applied Biosystems, Foster City, CA, USA). Primer sequences were designed according to the GeneBank database using the Beacon Designer software (Premier Biosoft, Palo Alto, CA, USA). GAPDH was used as the internal control.

\section{Statistical analysis}

One-way analysis of variance and Newman-Keuls post hoc analysis were performed using GraphPad Prism 5 (GraphPad Software, Inc., La Jolla, CA, USA) to determine the significance of mean differences between groups. A a-level of $P<0.05$ was considered statistically significant and all data are expressed as Mean \pm SEM values.

\section{RESULTS}

Composition and antioxidant activity of the steamed ginger extract

We first measured the total polyphenol and flavonoid contents of the two different extracts of steamed ginger. Compared to SGW, SGE exerted 4-fold and 30-fold higher levels of polyphenols and flavonoids, respectively (Table 1). It is known that plants or vegetables containing high levels of polyphenols or flavonoids have potent antioxidant activities. To evaluate the effects of steamed ginger on antioxidant capacity, we measured the reducing power and free radical scavenging activity of the two different extracts of steamed ginger. Reducing power was significantly higher in SGE than in SGW. Moreover, the DPPH and $\mathrm{ABTS}^{+}$radical scavenging activities of SGE were markedly greater than those of SGW (Table 2).

Table 2. Composition of experimental diets

\begin{tabular}{lcc}
\hline \multicolumn{1}{c}{ Component $\left(\mathrm{g} 100 \mathrm{~g}^{-1}\right)$} & Normal diet (ND) & High-fat diet (HFD) \\
\hline Casein & 18.96 & 25.84 \\
Cystine & 0.28 & 0.39 \\
Corn starch & 29.86 & - \\
Maltodextrin & 3.32 & 16.15 \\
Sucrose & 33.17 & 8.89 \\
Cellulose & 4.74 & 4.46 \\
Soybean oil & 2.37 & 3.23 \\
Lard & 1.9 & 31.66 \\
Mineral & 0.95 & 1.29 \\
Dicalcium phosphate & 1.23 & 1.68 \\
Calcium carbonate & 0.52 & 0.71 \\
Potassium citrate & 1.56 & 2.13 \\
Vitamin mix & 0.95 & 1.29 \\
Choline bitartrate & 0.19 & 0.26 \\
Kcal g & 3.85 & 5.24 \\
\hline ND, 10\% of energy as fat (D12450B); HFD, $60 \%$ of energy as fat (D12492)
\end{tabular}

Table 1. Composition and radical scavenging activity of different extracts of steamed ginger

\begin{tabular}{|c|c|c|c|c|c|c|c|}
\hline & \multirow{2}{*}{$\begin{array}{l}\text { 6-gingerol } \\
(\mathrm{mg} / \mathrm{kg})\end{array}$} & \multirow{2}{*}{$\begin{array}{l}\text { 6-shogaol } \\
(\mathrm{mg} / \mathrm{kg})\end{array}$} & \multirow{2}{*}{$\begin{array}{l}\text { Polyphenol } \\
\text { (mg GAE/g) }\end{array}$} & \multirow{2}{*}{$\begin{array}{l}\text { Flavonoid } \\
\text { (mg QE/g) }\end{array}$} & \multirow{2}{*}{$\begin{array}{l}\text { Reducing power } \\
\text { (A700) }\end{array}$} & \multicolumn{2}{|c|}{ Radical scavenging activity (\%) } \\
\hline & & & & & & DPPH & ABTS \\
\hline GSW & $2,551.75 \pm 33.79$ & $329.77 \pm 8.49$ & $36.41 \pm 0.60$ & $2.03 \pm 0.03$ & $0.026 \pm 0.001$ & $34.77 \pm 0.40^{c}$ & $22.91 \pm 0.26^{c}$ \\
\hline GSE & $20,437.13 \pm 228.75$ & $12,323.50 \pm 17.81$ & $122.9 \pm 0.43^{*}$ & $64.33 \pm 0.88^{*}$ & $0.035 \pm 0.001^{*}$ & $80.27 \pm 0.19^{b}$ & $88.34 \pm 0.31^{b}$ \\
\hline Trolox & - & - & - & - & - & $92.88 \pm 0.04^{\mathrm{a}}$ & $99.24 \pm 0.04^{\mathrm{a}}$ \\
\hline
\end{tabular}

All values are expressed as Means $\pm \mathrm{SD}$. Values with asterisk or different letters in a column denote statistical difference $(P<0.05)$.

SGW, water extract of steamed ginger; SGE, ethanolic extract of steamed ginger 
(A)

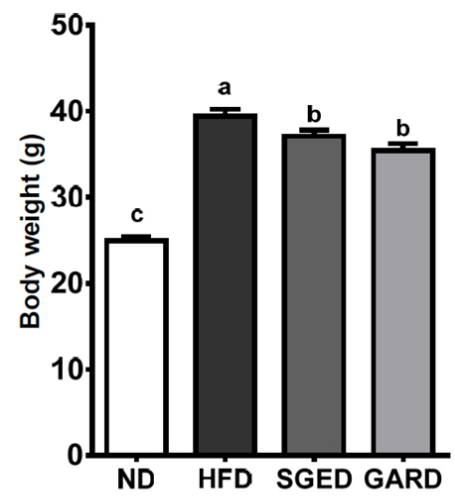

(B)

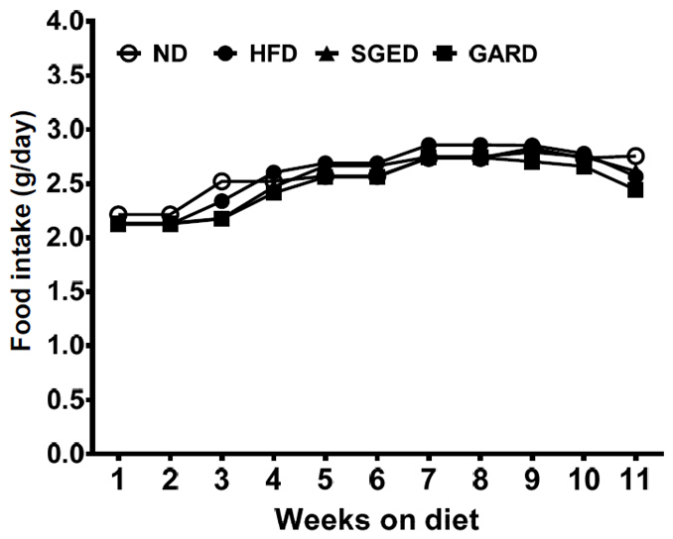

Fig. 1. Body weight and food intake of SGE-fed mice with DIO for 12 weeks. (A) Body weight $(B)$ Food intake Bars with different letters are significantly different $(P<0$ 05). Values are Means \pm SEM. $n=10$. ND, normal diet; HFD, high-fat diet, SGED, HFD with the addition of $200 \mathrm{mg} / \mathrm{kg}$ of SGE; GARD, HFD with the addition $200 \mathrm{mg} / \mathrm{kg}$ of garcinia.

(A)

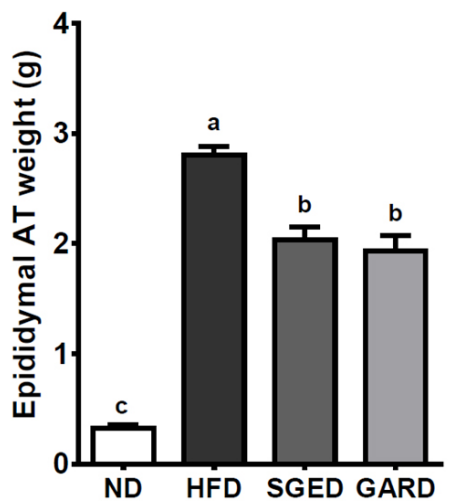

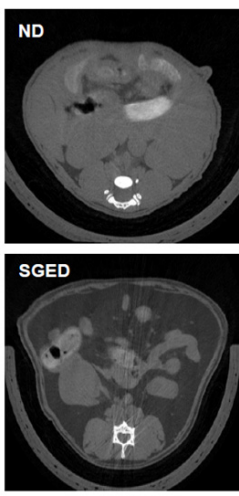

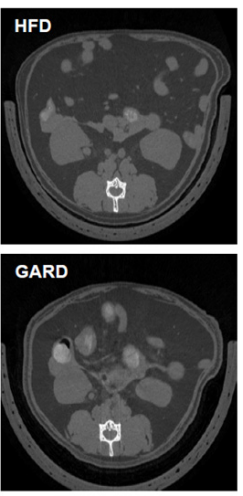

(C)
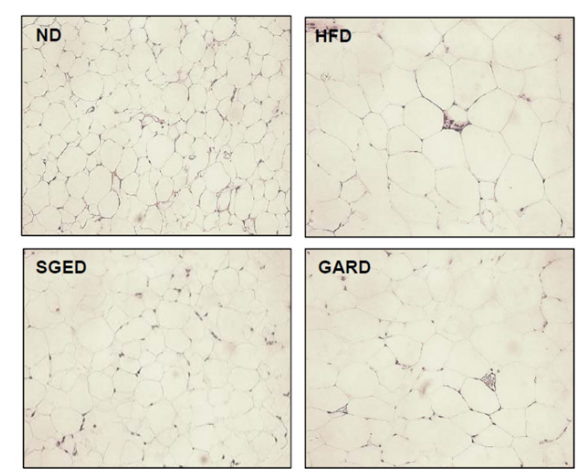

Fig. 2. Effect of SGE on epididymal adipose tissue of mice with DIO for 12 weeks. (A) Epididymal adipose tissue weight, (B) micro-CT, and (C) histology of epididymal adipose tissue. Bars with different letters are significantly different $(P<0.05)$. Values are Means \pm SEM. $n=10 . N D$, normal diet; HFD, high-fat diet, SGED, HFD with the addition of 200 mg/kg of SGE; GARD, HFD with the addition $200 \mathrm{mg} / \mathrm{kg}$ of garcinia.

Effects of SGE on body and tissue weight in HFD-induced obese mice

We next investigated the protective effect of SGE against obesity induced by HFD in C57BL/6J mice. The same concentration GAR, which is known for its antiobesity effect, was added to the diet of the positive control group. Although there was no significant difference in food intake of the ND and HFD groups, the HFD significantly increased the body weight of mice compared to that of the ND group (Fig. 1). Body weights in the SGED and GARD groups were significantly lower than that of the HFD group.

Effect of SGE on adipose tissue in HFD-induced obese mice

Next, we examined the effect of SGE on the mass of mouse epididymal fat pads. The weights of the epididymal fat pads were significantly higher in the HFD group compared to that in the ND group. However, SGE or GAR supplementation of the HFD significantly reduced the mass of the epididymal fat pads, as well visceral fat volume, as shown in micro-CT images, was reduced (Fig. 2A and 2B). Furthermore, SGE decreased the size of adipocytes in epididymal fat pads compared to that of pads in the HFD group (Fig. 2C)

Effect of SGE on serum chemistry in HFD-induced obese mice
Compared to the ND group, the serum glucose and insulin levels were significantly increased in the HFD group, whereas SGE or GAR supplementations markedly attenuated the increase (Fig. 3A and 3B). Furthermore, serum adiponectin levels were significantly increased in the SGED and GARD groups compared to that of the HFD group. The elevated serum leptin, ALT, and AST levels in HFD were significantly attenuated in SGED and GARD group (Fig. 3 D, 3E, and 3F). Among the serum lipids, HFD significantly increased serum TG, TC, and LDL-C levels compared to that in the ND group, whereas the HDL-C level in the HFD group was lower than that of the ND group. However, SGE supplementation attenuated the HFD-induced increases in serum TG, TC, and LDL-C (Fig. 4A, 4B, and 4C). The decrease in the serum HDL-C concentration in the HFD group was significantly attenuated in the SGED and GARD groups (Fig. 4D).

Effect of SGE on hepatic steatosis in HFD-induced obese mice We next investigated whether SGE or GAR supplementation can affect hepatic steatosis induced by HFD in C57BL/6J mice. The HFD-increased liver weights were significantly decreased by SGE or GAR supplementation (Fig. 5A). Furthermore, SGE and GAR reduced hepatic TG and TC levels (Fig. 5B). Histological analysis confirmed that hepatic TG accumulations in the SGED and 
(A)

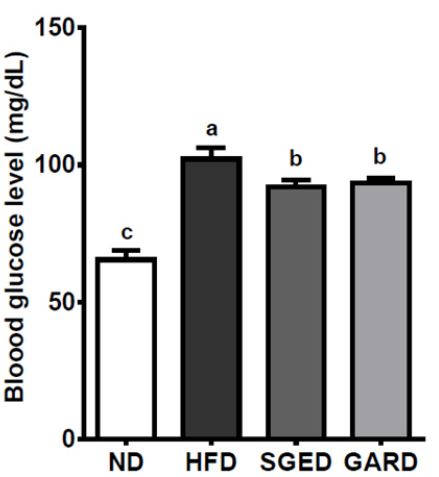

(D)

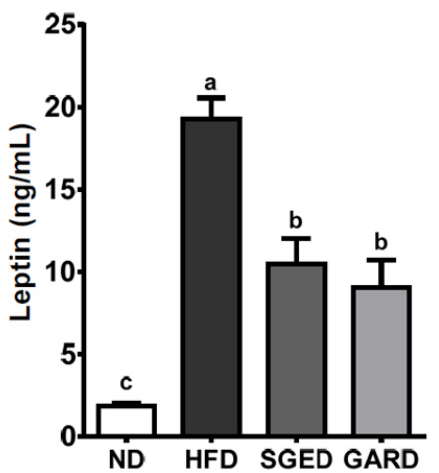

(B)

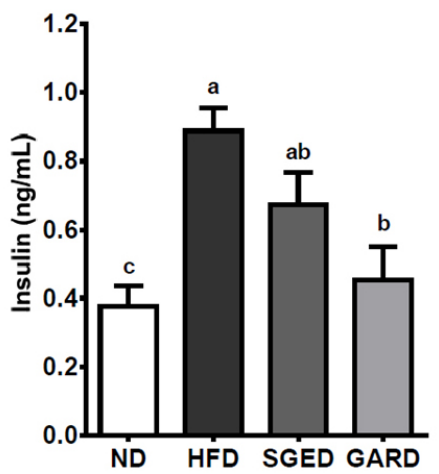

(E)

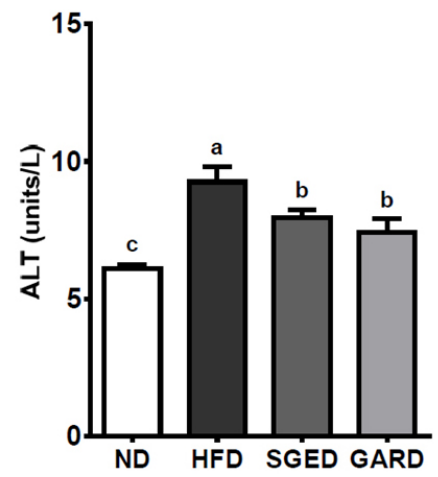

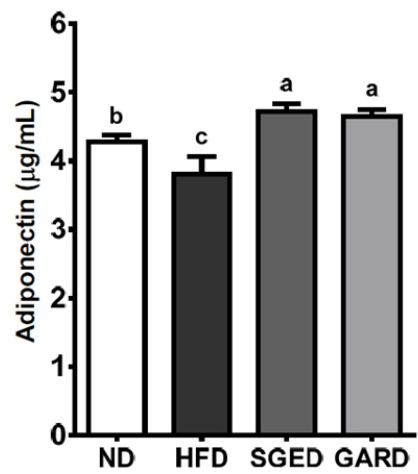

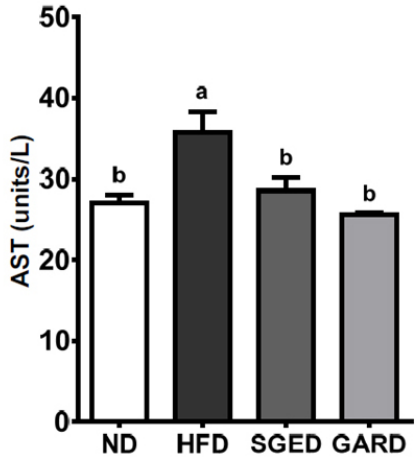

Fig. 3. Serum chemistry of SGE-fed mice with DIO for 12 weeks. (A) Blood glucose levels, (B) insulin levels, (C) adiponectin levels, (D) leptin levels, (E) ALT levels, and (F) AST levels. Bars with different letters are significantly different $(P<0.05)$. Values are Means \pm SEM. $n=10$. ND, normal diet; HFD, high-fat diet, SGED, HFD with the addition of 200 mg/kg of SGE; GARD, HFD with the addition $200 \mathrm{mg} / \mathrm{kg}$ of garcinia.

(A)

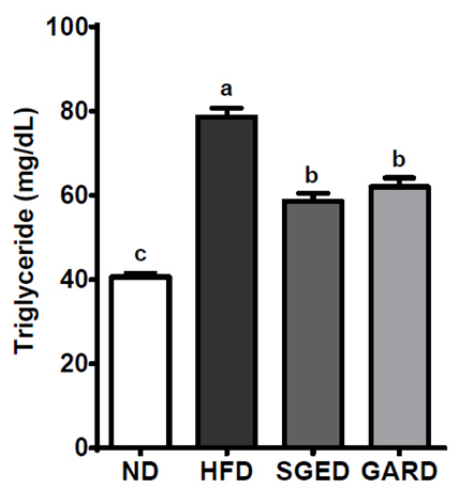

(C)

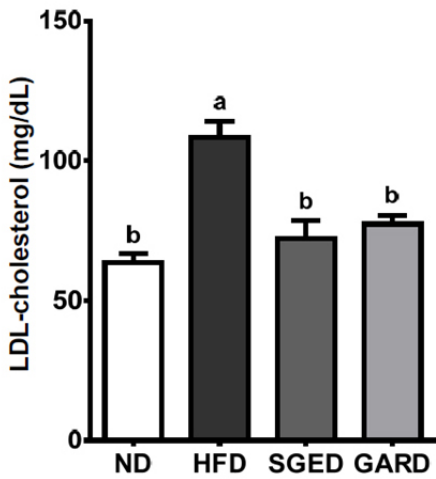

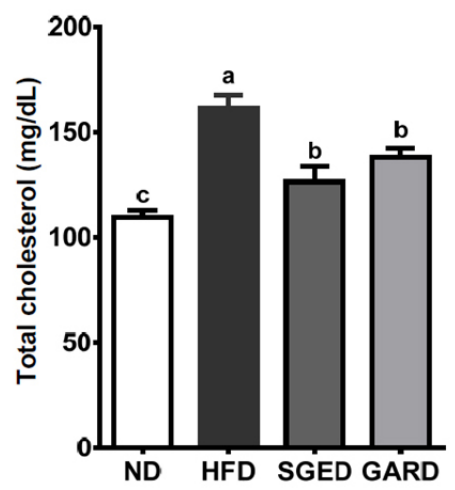

(D)

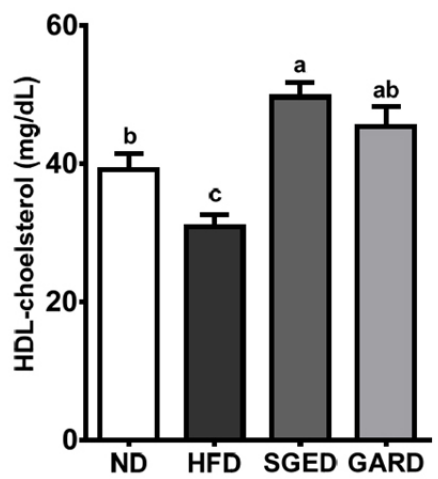

Fig. 4. Effects of SGE on serum lipids in mice with DIO fed for 12 weeks. (A) Triglyceride levels, (B) total cholesterol levels, (C) LDL cholesterol levels, and (D) HDL cholesterol levels. Bars with different letters are significantly different $(P<0.05)$. Values are Means \pm SEM. $\mathrm{n}=10$. ND, normal diet; HFD, high-fat diet, SGED, HFD with the addition of 200 mg/kg of SGE; GARD, HFD with the addition $200 \mathrm{mg} / \mathrm{kg}$ of garcinia. 
(A)

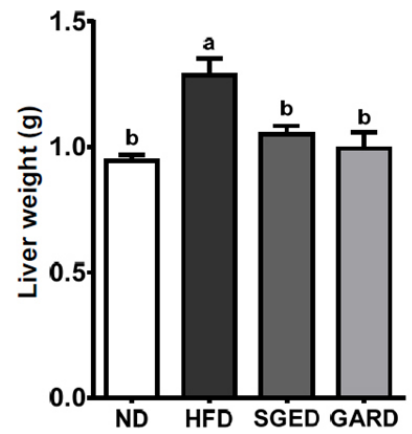

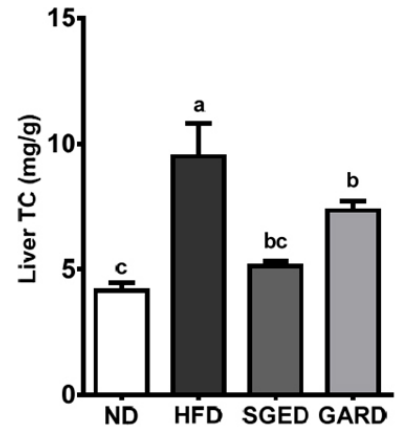

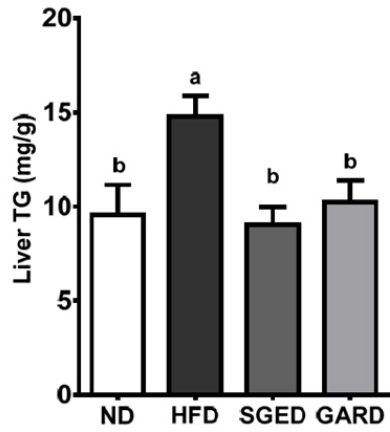

(C)
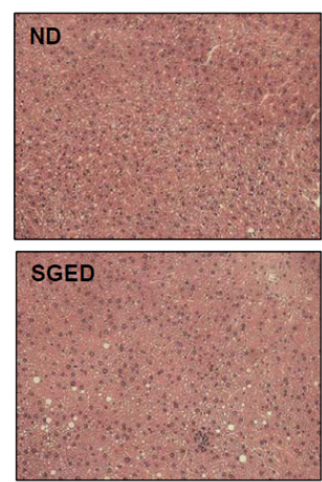
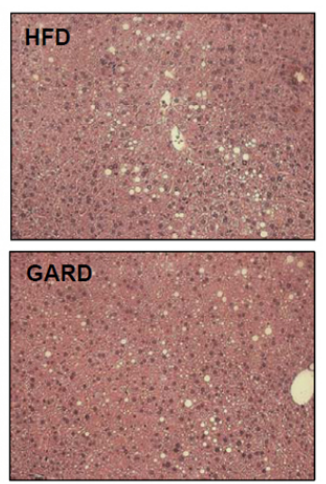

(D)

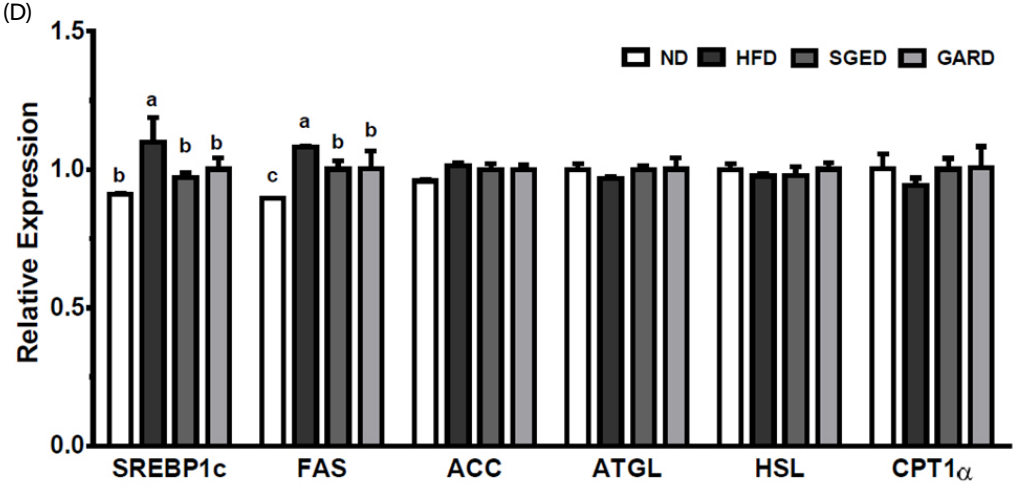

Fig. 5. Effects of SGE on lipid metabolism in liver of mice with DIO fed for 12 weeks. (A) Liver weight, (B) hepatic total cholesterol and triglyceride levels, (C) representative liver sections stained with H\&E, and (D) mRNA expressions of lipid metabolism-related genes. Bars with different letters are significantly different $(P<0.05)$. Values are Means \pm SEM. $n$ $=10$. ND, normal diet; HFD, high-fat diet, SGED, HFD with the addition of $200 \mathrm{mg} / \mathrm{kg}$ of SGE; GARD, HFD with the addition $200 \mathrm{mg} / \mathrm{kg}$ of garcinia.

GARD groups were lower than that in the HFD group (Fig. 5C). In the SGED and GARD groups, expressions of hepatic genes involved in lipid metabolism were significantly decreased, as shown by the lipogenic genes sterol regulatory elementbinding protein 1c (SREBP1c) and fatty acid synthase (FAS) (Fig. 5D).

\section{DISCUSSION}

Obesity is a principal risk factor in the pathogenesis of metabolic diseases such as CVD, NAFLD, type 2 diabetes, and cancers [31-32]. It has been defined as a medical condition with excessive fat accumulation concomitant with chronic oxidative stress and low-grade inflammation that lead to systemic changes in the body [4]. In obesity, oxidative stress occurs as a result of increased productions of local and/or systemic pro-inflammatory adipocytokines [33-35]. The increased and/or dysregulated productions of local adipocytokines in adipose tissue eventually lead to oxidative stress that can further induce low-grade systemic inflammation. Elevated oxidative stress in adipose tissue is one of the critical factors associated with obesity-associated pathogenic conditions. Therefore, reducing oxidative stress may enhance the obesity-associated metabolic complications [36]. The provision of dietary natural antioxidants is an attractive strategy for ameliorating oxidative damages that can further accelerate obesity-associated pathological conditions [37]. Whether treated as a spice, vegetable, or traditional medicine, ginger is well-known for its antioxidant activity and protective effects on obesity [38]. In the present study, we initially investigated the effects of steamed ginger extracts on radical scavenging activity. The levels of polyphenols and flavonoids, well-known dietary antioxidants, were higher in SGE than in SGW. This was accompanied by higher DPPH and $\mathrm{ABTS}^{+}$ radical scavenging activity in SGE than in SGW. Several studies have reported on the contents of phenolic compounds in ginger and their antioxidant activities [9]. Interestingly, dried and frozen ginger were shown to have different antioxidant activity levels, which was correlated with phenol and flavonoid content levels, than that of fresh ginger. For example, the antioxidant ability of dried ginger was higher than that of fresh ginger when assessed by DPPH, ABTS, and FRAP radical scavenging assays [12]. Similarly, drying and freezing have been shown to change total anthocyanin levels in blueberries and alter their antioxidant effects [39].

Recently, antioxidants, especially dietary polyphenols, and their roles in the prevention of obesity and obesity-related chronic and metabolic diseases have received research attention. Cellular and animal studies have demonstrated that dietary polyphenols have protective effects on obesity by inhibiting adipogenesis via a modulation of signaling pathways that regulate antioxidant and anti-inflammatory responses. Therefore, we next investigated whether SGE had a protective effect against obesity induced by HFD in C57BL/6J mice. The body fat and epididymal fat pad weights were significantly increased in DIO mouse model, whereas SGE or GAR supplementation decreased those weight gains. Furthermore, both SGE and GAR supplements significantly reduced the HFD-induced increases 
in serum lipids. The hypocholesterolemic and hypolipidemic effects of ethanolic ginger extracts have been reported in several studies. In rats, the aqueous extract of ginger produced a significant reduction of TC, TG, and LDL-C levels, but not a significant increase in $\mathrm{HDL}-\mathrm{C}$ when compared to rats fed a hypercholesterolemic diet [40]. The combination of ginger extract and aerobic training significantly reduced TG, TC, and LDL cholesterol concentrations in high-fat-fed rats [41]. An ethanol extract of ginger ( $200 \mathrm{mg} / \mathrm{kg}$ ) exerted a hypolipidemic effect in cholesterol-fed rabbits by lowering marked rises in body weight, glucose, insulin, TC, TG, LDL-C, free fatty acids and phospholipid levels in the serum of rats [42]. Moreover, an ethanolic extract of ginger $(200 \mathrm{mg} / \mathrm{kg})$ significantly lowered serum TC, TG, and increased HDL cholesterol levels in diabetic dyslipidemia induced by streptozotocin (STZ) in rats; furthermore, the extract improved thiobarbituric acid reactive substances (TBARS) lipid peroxidation in the liver and pancreas [43].

In this study, SGE or GAR exerted a significant hypoglycemic effect by improving blood glucose levels and insulin levels in mice with DIO. Consistent with our results, previous studies have reported the hypoglycemic properties of ginger in different animal models. An aqueous extract of ginger produced an antihyperglycaemic effect in STZ-induced diabetic rats by affecting the activities of glycolytic enzymes. Leptin and adiponectin are essential adipocytokines and levels in the blood are closely associated with obesity. In obesity, the levels of leptin increases and the levels of adiponectin decreases. SGE significantly decreased elevated serum leptin levels in our HFD group. Adiponectin levels are inversely correlated with body fat and insulin resistance. The hypoglycemic effects of SGE may be affected by the regulation of these adipocytokines. Consistent with this study, the protective effects of an ethanolic extract of ginger on metabolic syndrome development were shown by the significant reductions of marked rises in body weights, glucose, insulin, TC, LDL-C, TG, free fatty acids and phospholipid levels in the serum of the rats [44].

Adipose tissue expansion is associated with insulin resistance and dyslipidemia in obesity. The expansion of adipose tissue by hypertrophy, i.e., enlargement of adipocyte size, is a predictor of obesity. Our results showed that, when compared with HFD fed mice, SGE can significantly decrease adipose tissue weight concomitant with a decrease in adipocyte size. Furthermore, the protective effects of SGE in epididymal adipose tissue weight gain was confirmed by the results of micro-CT scanning. These results suggest that SGE can ameliorate metabolic disorders in glucose and lipid metabolism induced by HFD.

Obesity is closely associated with the prevalence NAFLD and nonalcoholic steatohepatitis. The liver is a primary organ for lipid and glucose metabolism, and one of the main characteristics of obesity is hepatic steatosis, ectopic lipid accumulation in the liver. Therefore, we next investigated the effects of SGE on HFD-induced steatosis in mice. The steamed ginger supplements produced a decrease in liver weight, which was supported by the reduction of hepatic TC and TG accumulation in the mice with DIO. Furthermore, histological examination of livers confirmed that the increased in hepatic lipid accumulation induced by HFD were decreased in the SGED group. The ALT and AST levels, a marker for liver damage, were significantly attenuated by steamed ginger supplementation. To understand the mechanisms underlying the protective effect of SGE on steatosis, we measured expressions of hepatic genes involved in lipid metabolism. SREBP1c is a transcription factor that regulates lipogenic genes such as FAS. Both CPT1a and acyl-coenzyme $A$ oxidase are rate-limiting enzymes for fatty acid $\beta$-oxidation that are present in mitochondria and peroxisomes, respectively. Adipose triglyceride lipase and hormone sensitive lipase are key enzymes involved in lipolysis. There was a marked induction of hepatic lipogenic gene expressions (e.g., such as SREBP-1c and FAS) by HFD, whereas SGE supplementation significantly decreased the HFD-induced increases. However, there were no differences in the expressions of genes involved in fatty acid $\beta$-oxidation and lipolysis. Several studies have reported that a ginger extract can improve lipid profiles by regulating genes involved in lipid metabolism. It has been reported that a ginger extract $(250 \mathrm{mg} / \mathrm{kg} /$ day) improved the lipid profile and attenuated the increase of plasma levels of glucose, insulin, and leptin in a HFD, along with a higher liver expression of PPARa, PPARy, and GLUT-2, an enhancement of plasma adiponectin levels, and a reduced liver expression of SREBP1c [45]. Gingerol- and shogaol-enriched extracts have significantly and dose-dependently decreased plasma TC and liver cholesterol via alteration of the expression of genes involved in cholesterol absorption and alteration of bile acid secretion with increasing amounts of ginger in hamsters fed a high-cholesterol diet [46]. Therefore, the mechanisms associated with the hypocholesterolemic and hypolipidemic effects produced by steamed ginger involve the regulation of hepatic lipogenesis.

In conclusion, steamed ginger can exert a free radical scavenging activity and protective effects on serum lipids and hepatosteatosis by regulating genes involved in hepatic adipogenesis and lipogenesis in HFD-induced obese mice. Our results suggest that the steamed ginger effects may be attributed to the inhibition of fat accumulation in adipose tissue and lipogenesis in the liver. Further study is needed to investigate the mechanisms underlying the effects of SGE supplementation on nonalcoholic steatohepatitis, NAFLD with inflammation. Furthermore, the present study supports previous reports about the health benefits of ginger extracts and indicates the potential of using ginger extracts to reduce obesity.

\section{ACKNOWLEGMENTS}

This work was supported by the Ministry of Agriculture, Food and Rural Affairs (MAFRA), through the 2015 Healthy Local Food Branding Project of the Rural Resources Complex Industrialization Support Program.

\section{CONFLICT OF INTEREST}

The authors declare no potential conflicts of interests.

\section{ORCID}

Hee-Jeong Kim: https://orcid.org/0000-0003-4365-3194

Bohkyung Kim: https://orcid.org/0000-0002-5921-2185

Eun-Gyung Mun: https://orcid.org/0000-0001-9476-5773 
Soon-Yeon Jeong: https://orcid.org/0000-0001-8329-5403

Youn-Soo Cha: https://orcid.org/0000-0001-5579-650x

\section{REFERENCES}

1. Botchlett R, Woo SL, Liu M, Pei Y, Guo X, Li H, Wu CDC. Nutritional approaches for managing obesity-associated metabolic diseases. J Endocrinol 2017;233:R145-71.

2. Abdali D, Samson SE, Grover AK. How effective are antioxidant supplements in obesity and diabetes? Med Princ Pract 2015;24: 201-15.

3. Matsuda M, Shimomura I. Increased oxidative stress in obesity: implications for metabolic syndrome, diabetes, hypertension, dyslipidemia, atherosclerosis, and cancer. Obes Res Clin Pract 2013;7:e330-41.

4. Furukawa $S$, Fujita $T$, Shimabukuro $M$, Iwaki $M$, Yamada $Y$, Nakajima Y, Nakayama O, Makishima M, Matsuda M, Shimomura I. Increased oxidative stress in obesity and its impact on metabolic syndrome. J Clin Invest 2004;114:1752-61.

5. Pisoschi AM, Pop A. The role of antioxidants in the chemistry of oxidative stress: a review. Eur J Med Chem 2015;97:55-74.

6. Chrubasik S, Pittler MH, Roufogalis BD. Zingiberis rhizoma: a comprehensive review on the ginger effect and efficacy profiles. Phytomedicine 2005;12:684-701.

7. Haniadka R, Saldanha E, Sunita V, Palatty PL, Fayad R, Baliga MS. A review of the gastroprotective effects of ginger (Zingiber officinale Roscoe). Food Funct 2013;4:845-55.

8. Marx W, McKavanagh D, McCarthy AL, Bird R, Ried K, Chan A, Isenring $L$. The effect of ginger (Zingiber officinale) on platelet aggregation: a systematic literature review. PLoS One 2015;10: e0141119.

9. Tohma H, Gulcin I, Bursal E, Goren AC, Alwasel SH, Koksal E. Antioxidant activity and phenolic compounds of ginger (Zingiber officinale Rosc.) determined by HPLC-MS/MS. J Food Meas Charact 2017;11:556-66.

10. Sakulnarmrat K, Srzednicki G, Konczak I. Antioxidant, enzyme inhibitory and antiproliferative activity of polyphenolic-rich fraction of commercial dry ginger powder. Int J Food Sci Technol 2015;50: 2229-35.

11. Jelled A, Fernandes A, Barros L, Chahdoura H, Achour L, Ferreira IC, Ben Cheikh H. Chemical and antioxidant parameters of dried forms of ginger rhizomes. Ind Crops Prod 2015;77:30-5.

12. Guo J, Wu H, Du L, Zhang W, Yang J. Comparative antioxidant properties of some gingerols and shogaols, and the relationship of their contents with the antioxidant potencies of fresh and dried ginger (Zingiber officinale Roscoe). J Agr Sci Tech 2014;16:1063-72.

13. Shi CJ, Wen XS, Gao HF, Liu ZH, Xu XK, Li LF, Shen T, Xian CJ. Steamed root of Rehmannia glutinosa Libosch (Plantaginaceae) alleviates methotrexate-induced intestinal mucositis in rats. J Ethnopharmacol 2016;183:143-50.

14. Jun HI, Yang JH, Choi JY, Lee SH, Song GS, Kim KS, Kim YS. Changes in volatile flavor compounds in steam-dried Allium hookeri root. Food Sci Biotechnol 2016;25:1327-31.

15. Gu CZ, Lv JJ, Zhang XX, Yan H, Zhu HT, Luo HR, Wang D, Yang $\mathrm{CR}$, Xu M, Zhang YJ. Minor dehydrogenated and cleavaged dammarane-type saponins from the steamed roots of Panax notoginseng. Fitoterapia 2015;103:97-105.

16. Gu CZ, Lv JJ, Zhang XX, Qiao YJ, Yan H, Li Y, Wang D, Zhu HT,
Luo HR, Yang CR, Xu M, Zhang YJ. Triterpenoids with promoting effects on the differentiation of PC12 cells from the steamed roots of panax notoginseng. J Nat Prod 2015;78:1829-40.

17. Nakamura Y, Kuranouchi T, Ohara-Takada A, Katayama K. The effects of $\beta$-amylase activity and starch pasting temperature on maltose generation in steamed storage roots of sweet potato. J Jpn Soc Food Sci 2014;61:577-85.

18. Fletes-Arjona VM, Soto-Dominguez A, Garcia-Garza R, Moran-Martinez J, Benitez-Valle C, Castaneda-Martinez A, Montalvo-Gonzalez R, Becerra-Verdin EM. Morphologic alterations in the respiratory tract of wistar rats induced by steams of the root of Hierba del Zorrillo (Petiveria alliacea) from southwest of Mexico. Int J Morphol 2013;31:121-7.

19. Zhang J, Yu K, Millar A, Gao Y, Ma B, Kang L, Yu H. Comparison of extracts from dry and alcohol-steamed root of Polygonatum kingianum (Huang Jing) by sub-2- $\mu \mathrm{m}-\mathrm{LC}-\mathrm{TOF}-\mathrm{MS}$. Curr Trends Mass Spectrom 2011;9:30-5.

20. Liu Z, Liu Y, Chao Z, Song Z, Wang C, Lu A. In vitro antioxidant activities of maillard reaction products produced in the steaming process of Polygonum multiflorum root. Nat Prod Commun 2011;6:55-8.

21. Sun $S$, Wang $C Z$, Tong $R$, Li $X L$, Fishbein $A$, Wang $Q$, He TC, Du $W$, Yuan CS. Effects of steaming the root of Panax notoginseng on chemical composition and anticancer activities. Food Chem 2010;118:307-14.

22. Arjona CA, Rodriguez-Fragoso L, Rosado-Vallado M, Fitz-Aranda $C$, Mendoza-Rivera B, Reyes-Esparza J. Pharmacological and toxicological evaluation of methanolic extracts from leaves, steam and roots of a Cnidoscolus plant. FASEB J 2010;24.

23. Turkmen N, Sari F, Velioglu YS. Effects of extraction solvents on concentration and antioxidant activity of black and black mate tea polyphenols determined by ferrous tartrate and Folin-Ciocalteu methods. Food Chem 2006;99:835-41.

24. Zhishen J, Mengcheng T, Jianming W. The determination of flavonoid contents in mulberry and their scavenging effects on superoxide radicals. Food Chem 1999;64:555-9.

25. Mau JL, Lin HC, Song SF. Antioxidant properties of several specialty mushrooms. Food Res Int 2002;35:519-26.

26. Hatano T, Edamatsu R, Hiramatsu M, Mori A, Fujita Y, Yasuhara T, Yoshida T, Okuda T. Effects of the interaction of tannins with co-existing substances. 6 . Effects of tannins and related polyphenols on superoxide anion radical, and on 1,1-diphenyl-2-picrylhydrazyl radical. Chem Pharm Bull (Tokyo) 1989;37:2016-21.

27. Re R, Pellegrini N, Proteggente A, Pannala A, Yang M, Rice-Evans C. Antioxidant activity applying an improved ABTS radical cation decolorization assay. Free Radic Biol Med 1999;26:1231-7.

28. Thomas SS, Kim M, Lee SJ, Cha YS. Antiobesity effects of purple perilla (Perilla frutescens var. acuta) on adipocyte differentiation and mice fed a high-fat Diet. J Food Sci 2018:83-2384-93.

29. Friedewald WT, Levy Rl, Fredrickson DS. Estimation of the concentration of low-density lipoprotein cholesterol in plasma, without use of the preparative ultracentrifuge. Clin Chem 1972;18: 499-502.

30. Kim M, Park JE, Song SB, Cha YS. Effects of black adzuki bean (Vigna angularis) extract on proliferation and differentiation of 3T3-L1 preadipocytes into mature adipocytes. Nutrients 2015;7:277-92.

31. Meigs JB, Wilson PW, Fox, Vasan RS, Nathan DM, Sullivan LM, D'Agostino RB. Body mass index, metabolic syndrome, and risk of 
type 2 diabetes or cardiovascular disease. J Clin Endocrinol Metab 2006;91:2096-12.

32. Keller KB, Lemberg L. Obesity and the metaboic syndrome. Am J Crit Care 2003;12:167-70.

33. Fernández-Sánchez A, Madrigal-Santillán E, Bautista M, Esquivel-Soto J, Morales-González A, Esquivel-Chirino C, Durante-Montiel I, Sánchez-Rivera G, Valadez-Vega C, Morales-González JA. Inflammation, oxidative stress, and obesity. Int J Mol Sci 2011;12:3117-32.

34. Bondia-Pons I, Ryan L. Martinez JA. Oxidative stress and inflammation interactions in human obesity. J Physiol Biochem 2012;68: 701-11.

35. Galassetti P. Inflammation and oxidative stress in obesity, metabolic syndrome, and diabetes. Exp Diabetes Res 2012;2012:943706

36. Marseglia L, Manti S, D'Angelo G, Nicotera A, Parisi E, Di Rosa G, Gitto $E$, Arrigo T. Oxidative stress in obesity: a critical component in human diseases. Int J Mol Sci 2014;16:378-400.

37. Valdecantos MP, Pérez-Matute P, Martínez JA. Obesity and oxidative stress: role of antioxidant supplementation. Rev Invest Clin 2009;61:127-39.

38. Wang J, Ke W, Bao R, Hu X, Chen F. Beneficial effects of ginger Zingiber officinale Roscoe on obesity and metabolic syndrome: a review. Ann N Y Acad Sci 2017;1398:83-98.

39. Lohachoompol V, Srzednicki G, Craske J. The change of total anthocyanins in blueberries and their antioxidant effect after drying and freezing. J Biomed Biotechnol 2004;2004:248-52.

40. EIRokh el SM, Yassin NA, El-Shenawy SM, Ibrahim BM. Antihyper- cholesterolaemic effect of ginger rhizome (Zingiber officinale) in rats. Inflammopharmacology 2010;18:309-15.

41. Khosravani M, Azarbayjani MA, Abolmaesoomi M, Yusof A, Abidin NZ, Rahimi E, Feizolahi F, Akbari M, Seyedjalali S, Dehghan F. Ginger extract and aerobic training reduces lipid profile in high-fat fed diet rats. Eur Rev Med Pharmaco 2016;20:1617-22.

42. Bhandari U, Sharma JN, Zafar R. The protective action of ethanolic ginger (Zingiber officinale) extract in cholesterol fed rabbits. J Ethnopharmacol 1998;61:167-71.

43. Bhandari U, Kanojia R, Pillai KK. Effect of ethanolic extract of Zingiber officinale on dyslipidaemia in diabetic rats. J Ethnopharmacol 2005;97:227-30.

44. Nammi S, Sreemantula S, Roufogalis BD. Protective effects of ethanolic extract of Zingiber officinale rhizome on the development of metabolic syndrome in high-fat diet-fed rats. Basic Clin Pharmacol Toxicol 2009;104:366-73.

45. de Las Heras N, Valero-Muñoz M, Martín-Fernández B, Ballesteros S, López-Farré A, Ruiz-Roso B, Lahera V. Molecular factors involved in the hypolipidemic- and insulin-sensitizing effects of a ginger (Zingiber officinale Roscoe) extract in rats fed a high-fat diet. Appl Physiol Nutr Metab 2017;42:209-15.

46. Lei L, Liu Y, Wang X, Jiao R, Ma KY, Li YM, Wang L, Man SW, Sang $S$, Huang $Y$, Chen ZY. Plasma cholesterol-lowering activity of gingerol- and shogaol-enriched extract is mediated by increasing sterol excretion. J Agric Food Chem 2014;62:10515-21. 